\title{
Will luminescent solar concentrators surpass the $10 \%$ device efficiency limit?
}

\section{Wilfried van Sark}

Nanosized particles with low overlap between their absorption and emission spectra allow more of the sun's light energy to be captured.

Solar photovoltaic (PV) technology is continuously increasing conversion efficiency while reducing cost. It has been sufficiently successful that by the end of 2013, installed capacity worldwide had reached $134 \mathrm{GW},{ }^{1}$ with $90 \%$ of market share made up of technology based on crystalline silicon (c-Si) wafers installed on rooftops (up to several kilowatts) or fields (tens to hundreds of megawatts). Despite this, PV still has a long way to go to reach multiterawatt capacity and play a significant role in our future electricity supply. Many alternative technologies are under development that will compete with standard c-Si technology, such as inorganic thin films, but also systems that concentrate light to a high (1000 times) or low (up to 10 times) extent. One such development is luminescent solar concentrators (LSCs), which are low concentration and relatively low cost, and they can also be shaped and colored. As a consequence, they are suitable for use as building façade elements with aesthetically appealing surfaces of variable shape and color.

LSCs began to be developed in the 1970s as an alternative approach for reducing PV technology costs. ${ }^{2,3}$ In LSCs, both direct and diffuse light is concentrated by a factor of 5-10. LSCs typically consist of a plastic plate, in which luminescent species are dispersed. These species absorb incident light and emit light at a wavelength that is a red-shifted with respect to the absorbed wavelength, as a result of the Stokes' shift of the particular luminescent species. The majority of the emission (some is lost) is guided by total internal reflection to a solar cell at the side (see Figure 1). ${ }^{4}$ Ideally, an LSC should fulfill six requirements. ${ }^{5,6}$ First, it should absorb all photons with wavelength $>950 \mathrm{~nm}$ and emit them red-shifted at $\sim 1000 \mathrm{~nm}$ for use with c-Si solar cells. Second, it should have minimal spectral overlap between absorption and emission spectra to keep re-absorption losses

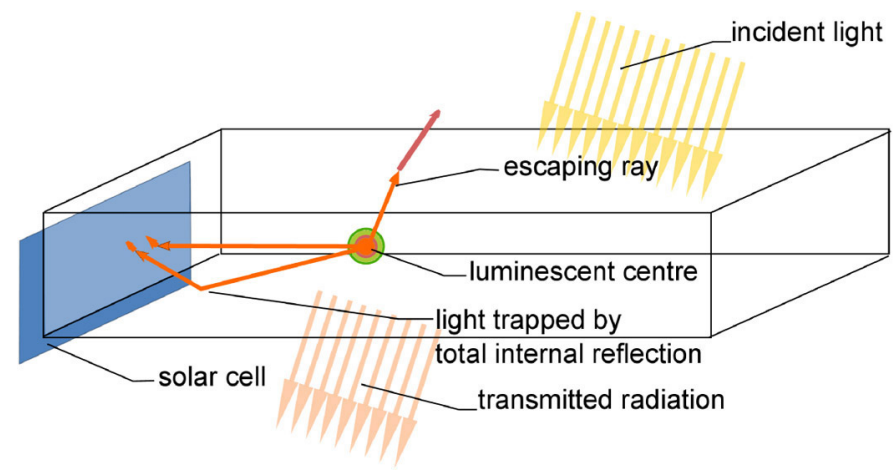

Figure 1. Schematic 3D view of a luminescent concentrator. AM1.5 light (mimicking the solar spectrum at temperate latitudes) is incident at the top. The light is absorbed by luminescent species, and its luminescence is randomly emitted. Part of the emission falls within the escape cone and is lost from the luminescent concentrator at the surfaces. Another part is guided to the solar cell by total internal reflection. ${ }^{4}$

as low as possible. Third, near-unity luminescence quantum efficiency (LQE) is required. Fourth, an ideal LSC has low escape cone losses. Fifth, it should be stable outdoors for longer than 10 years. Finally, it should be easy to manufacture at low cost. However, material issues have hampered efficiency improvements in LSCs, in particular re-absorption of light emitted by luminescent species. Today's efficiency record is $7.1 \%{ }^{7}$

The luminescent species typically used are organic dyes, although the use of nanosized inorganic particles is growing and attracting increasing attention from researchers. In general, the absorption spectra of dyes and nanoparticles overlap their emission spectra, leading to certain non-zero probability for a luminescent species to absorb the light emitted by the same species. This may occur successively such that an absorbed photon never reaches the solar cell at the side of the LSC plate. Reabsorption

Continued on next page 
Table 1. Classifications of luminescent species according to their loss. The larger the Stokes' shift, the lower the loss. CdSe: Cadmium selenide. CdTe: Cadmium telluride. ZnS: Zinc sulfide. ${ }^{4}$

\begin{tabular}{|l|l|l|}
\hline Loss & Group & Stokes' Shift \\
\hline Strong & CdSe nanocrystals & $5 \mathrm{~nm}$ \\
\hline Moderate & $\begin{array}{l}\text { Lumogen dye } \\
\text { Rhodamine dye }\end{array}$ & $10-20 \mathrm{~nm}$ \\
\hline Low & $\begin{array}{l}\text { Type-II heteronanocrystals: } \\
\text { CdTe/CdSe/ZnS, core/multishell } \\
\text { CdTe/CdSe dot-core/rod-shell }\end{array}$ & $\sim 120 \mathrm{~nm}$ \\
\hline
\end{tabular}

thus leads to increased loss and, as a consequence, this limits the size of LSC plates and the maximum concentration ratio. ${ }^{8}$ We have worked to minimize re-absorption by reducing the overlap of the luminescent species' absorption and emission spectra.

We first quantified reabsorption by defining a self-absorption cross section. ${ }^{4} 9$ We performed experiments on liquid LSCs, that is, cuvettes filled with luminescent species with different Stokes' shifts. The self-absorption cross-section of the commercially available dyes Rhodamine 6G (LQE $=95 \%)$ and Lumogen Orange (LQE $=95 \%$ ) were calculated to be $8.5 \%$ and $6.7 \%$, respectively. We also prepared luminescent nanocrystals with different shapes-either dot-core (the core is a spherical dot), rod-shell (the shell is more of a rod and non-spherical), or core/multishell (both core and multishell are spherical)and determined their reabsorption. ${ }^{10}$ For Type I (cadmium selenide, CdSe), Type-II-iso (cadmium telluride / cadmium selenide / zinc sulfide, CdTe/CdSe/ZnS core/multishell), and Type-II-an (CdTe/CdSe dot-core/rod-shell) nanocrystals, the self-absorption cross sections were $52.2 \%, 2.5 \%$, and $0.2 \%$, respectively. LQE of the nanocrystals was $27 \%$ and $48 \%$, for CdSe, and Type-II-iso nanocrystals, respectively.

We detected the emission intensity perpendicular to the excitation direction at the side of the cuvette as a function of excitation distance from the side. Emission intensity losses depended on the optical path length, and we were able to classify the luminescent species into three distinct groups according to their loss (see Table 1). We found that the larger the Stokes' shift, the lower the intensity loss. ${ }^{4}$

Using a validated combined ray-tracing/Monte-Carlo model, we further demonstrated that the self-absorption cross section is a meaningful criterion for evaluating self-absorption losses in LSCs. Interestingly, improving the quantum yield reduces self-absorption losses only if the self-absorption is prevalent. ${ }^{9}$ Recently, Erickson and coworkers reported results on zero-reabsorption zinc selenide nanocrystals doped with manganese. ${ }^{11}$ These QDs showed maxima in their absorption spectrum at 396nm and in their emission spectrum at 582nm. Although no efficiencies were reported, the concentration ratio was among the highest reported. The absorption maximum at 396nm clearly limits the LSC efficiency, and Erickson has suggested using CdSe doped with copper or indium phosphide nanocrystals to broaden the solar spectrum absorption. An even better match to the band gap of c-Si solar cells could be ytterbium-doped lead sulfide, which should have an emission maximum of $\sim 1000 \mathrm{~nm}$. An alternative approach has recently been reported by Meinardi and coworkers, ${ }^{12}$ who use the term 'Stokes-shift-engineering:' their LSCs with CdSe/CdS nanocrystals with giant shells did not show reabsorption losses.

In conclusion, (un)doped inorganic nanocrystals with high Stokes' shift and consequently low self-absorption cross section would be suitable candidates for use in highly efficient LSCs, provided their LQE can be increased to values approaching that of dyes. ${ }^{13}$ This undoubtedly would lead to device efficiency values beyond $10 \%$. We are now focusing on increasing LSC efficiency by developing high-LQE CdTe/CdSe Type-II nanocrystals, which requires improvements in synthesis.

The author gratefully acknowledges Zachar Krumer, Celso de Mello Donegá and Ruud Schropp in making this LSC endeavor a successful one. This work was partly financially supported by the Netherlands Foundation for Fundamental Research on Matter (FOM) and HyET Solar as part of their Joint Solar Program 2.

\section{Author Information}

\section{Wilfried van Sark}

Copernicus Institute

Utrecht University

Utrecht, The Netherlands

Wilfried van Sark is an associate professor. He has more than 30 years experience in the field of photovoltaics- $-\mathrm{c}-\mathrm{Si}$, amorphous silicon, III-V-ranging from cell development and spectrum conversion for next-generation photovoltaics to performance of solar cells and systems, policy, and cost development.

References

1. IEA-PVPS, PVPS Report Snapshot of Global PV 1992-2013, Report IEA-PVPS T1$24: 2014$

2. A. Goetzberger and W. Greubel, Solar energy conversion with fluorescent collectors, Appl. Phys. 14, pp. 123-139, 1977.

3. W. H. Weber and J. Lambe, Luminescent greenhouse collector for solar radiation, Appl. Opt. 15, pp. 2299-2300, 1976. 
4. Z. Krumer, S. J. Pera, R. J. A. Van Dijk-Moes, Y. Zhao, A. F. P. de Brouwer, E. Groeneveld, W. G. J. H. M. Van Sark, R. E. I. Schropp, and C. De Mello-Donegá, Tackling self-absorption in luminescent solar concentrators with type-II colloidal quantum dots, Sol. Energy Mater. Sol. Cells 111, pp. 57-65, 2013.

5. M. G. Debije and P. P. C. Verbunt, Thirty years of luminescent solar concentrator research: solar energy for the built environment, Adv. Energy Mater. 2, pp. 12-35, 2012. 6. B. C. Rowan, L. R. Wilson, and B. S. Richards, Advanced material concepts for luminescent solar concentrators, IEEE J. Sel. Topics Quant. Electron. 14, pp. 1312-1322, 2008.

7. L. H. Slooff, E. E. Bende, A. R. Burgers, T. Budel, M. Pravettoni, R. P. Kenny, E. D. Dunlop, and A. Büchtemann, A luminescent solar concentrator with $7.1 \%$ power efficiency, Phys. Stat. Sol. (RRL) 2, pp. 257-259, 2008.

8. D. J. Farrell and M. Yoshida, Operating regimes for second generation luminescent solar concentrators, Prog. Photovolt 20, pp. 93-99, 2012.

9. Z. Krumer, W. G. J. H. M. Van Sark, C. De Mello-Donegá, and R. E. I. Schropp, Exploration of parameters influencing the self-absorption losses in luminescent solar concentrators with an experimentally validated combined ray-tracing/Monte-Carlo model, Proc. SPIE 8821, p. 882104, 2013. doi:10.1117/12.2023682

10. C. De Mello Donegá, Synthesis and properties of colloidal heteronanocrystals, $\mathbf{C h e m}$. Soc. Rev. 40, pp. 1512-1546, 2011.

11. C. S. Erickson, L. R. Bradshaw, S. McDowall, J. D. Gilbertson, D. R. Gamelin, and D. L. Patrick, Zero-reabsorption doped-nanocrystal luminescent solar concentrators, ACS Nano 8, pp. 3461-3467, 2014.

12. F. Meinardi, A. Colombo, K. A. Velizhanin, R. Simonutti, M. Lorenzon, L. Beverina, R. Viswanatha, V. I. Klimov, and S. Brovelli, Large-area luminescent solar concentrators based on 'Stokes-shift-engineered nanocrystals' in a mass-polymerized PMMA matrix, Nat. Photon. 8, pp. 392-399, 2014.

13. W. G. J. H. M. van Sark, Recent developments in luminescent solar concentrators, Proc. SPIE 9178, p. 917801, 2014. In press. 